\title{
Knowledge and Attitudes of Ethiopian Nursing Staff Regarding Post-Operative Pain Management: A Cross-Sectional Multicenter Study
}

This article was published in the following Dove Press journal: Patient Related Outcome Measures

\author{
Mengesha Dessie' \\ Agmuas Asichale' \\ Tadesse Belayneh ${ }^{2}$ \\ Henos Enyew ${ }^{2}$ \\ Amare Hailekiros ${ }^{2}$ \\ 'Department of Anesthesia, College of \\ Medicine and Health Science, Debre \\ Berhan University, Debre Berhan, \\ Ethiopia; ${ }^{2}$ Department of Anesthesia, \\ College of Medicine and Health Science, \\ University of Gondar, Gondar, Ethiopia
}

Background: Pain management is one part of management in the postoperative period. The prevalence of moderate to severe postoperative pain and its functional interference is high in Ethiopian patients. In this study we aimed (1) to assess nurses' knowledge and attitudes regarding post-operative pain management; (2) to identify the factors of nurses' knowledge and attitudes. Method: A cross-sectional multicenter study was conducted. All nurses working in Amhara region referral hospitals were involved in the study. The Nurses' Knowledge and Attitudes Survey Regarding Pain (NKASRP) was used to measure the nurses' pain management knowledge and attitudes. Bivariable and multivariable logistic regression was used to identify factors associated with knowledge and attitude.

Results: A total of 433 nurses were included. Of the total respondents, 90.6\% of them had a bachelor's degree with work experience of between 1 to 5 years $(58.5 \%)$. Only $76(19.2 \%)$ participants got access to read journals and $66(16.7 \%)$ had taken training regarding postoperative pain management. The results showed that $56.5 \%$ [95\% $\mathrm{CI}=(51.6-61.3)]$ respondents had adequate knowledge and $8.9 \%[95 \% \mathrm{CI}=(6.1-11.6)]$ of them had positive attitudes towards POP management. Higher level of education $[\mathrm{AOR}=8.2 ; \mathrm{CI}=(2.51-26.83)]$, getting access to read journals $[\mathrm{AOR}=1.83 ; \mathrm{CI}=(1.01-3.30)]$, and taking POP management training $[\mathrm{AOR}=8.63 ; \mathrm{CI}=(3.67-20.28)]$ were statistically associated with adequate knowledge. Similarly, positive attitude towards postoperative pain management was associated with taking POP management training, available of pain management course in the curriculum, and getting access to read.

Conclusion: Although more than half of nurses in the study area had adequate knowledge towards POP management, only a small number had a positive attitude. Taking POP management training and getting access to read journals were significantly associated with good knowledge and attitude towards POP management; therefore, regular in-service training and getting accessing reading materials (such as journals or articles) are recommended to enhance quality service to patients.

Keywords: pain management, knowledge, attitude, nurses, postoperative pain

\section{Introduction}

Postoperative pain is a type of acute pain that is present in a surgical patient caused by preexisting surgical procedure. ${ }^{1}$ Globally, 312.9 million surgeries are performed with an estimated surgical rate of 4469/100,000 per year, as of 2012 report. $^{2}$ However, majority of surgical patients' experience acute postoperative pain (POP), although availability of perioperative interventions and management strategies. ${ }^{3,4}$ Evidence
Correspondence: Mengesha Dessie Medicine and Health Science, Debre Berhan University, PO Box 445, Debre Berhan, Ethiopia

Tel +25l 942042366

Email mengedessie@gmail.com 
showed that more than three quarter of patients report moderate, severe, or extreme postoperative pain in the postoperative period. ${ }^{3,5,6}$ In Ethiopia, the incidence of moderate to severe postoperative pain has been reported between $47-100 \%{ }^{7}$ Moreover, the treatment provided to patients is inadequate and not in line with international recommendations and standards. ${ }^{8}$

Undertreated postoperative pain is often associated with delayed mobility leading to delayed wound healing and deep vein thrombosis, pneumonia, chronic pain, coronary ischemia, myocardial infarction, depressed immune function. All of these affect economic and medical conditions, such as extended hospital stay, re-admissions, and patient dissatisfaction with medical care. ${ }^{6,9,10}$ However, optimal postoperative management facilitates early hospital discharge and reduces postoperative complications thereby increases patient satisfaction. ${ }^{11}$ Optimal postoperative pain management is an integral part of healthcare professional's (HCP) responsibility, which requires evaluation, treatment and re-evaluation. ${ }^{12}$ Repeated pain measurements and intervention done by nurses, for instance, results in effectiveness of epidural analgesia in postoperative patients. ${ }^{13}$ But for effective POP management, HCPs must have adequate knowledge, positive attitude and good skill. ${ }^{14}$ In most healthcare settings, nurses constitute the biggest population of the health workforce and have $24 \mathrm{hr}$ direct contact with patients than other $\mathrm{HCP},{ }^{15}$ and expected to play a vital role in managing patients' postoperative pain. ${ }^{16}$ Since pain relief has been recognized as a human right ${ }^{17}$ and considered as the "fifth" vital sign to be routinely assessed, nurses should give great attention to control postoperative pain. ${ }^{18}$ Nurses working in the surgical unit should have an adequate level of knowledge regarding different treatment modalities and their technique of administration. ${ }^{19}$ They should also consider patients' self-report of pain which is the best to evaluate pain perceptions and cognitive response. ${ }^{20}$ Similarly, they need to have a positive attitude towards assessing, documenting and treating POP to decrease POP related complications and enhance patient satisfaction. ${ }^{21}$ Work experience, level of education, and training are significantly associated with good postoperative pain management knowledge and attitude among nurse professionals. ${ }^{22,23}$ Despite the availability of medications and techniques, studies suggest insufficient pain treatment continues to be bedevil in post-surgical patients. ${ }^{7,9}$ Therefore, the purpose of this study was to evaluate nurses' knowledge and attitudes toward postoperative pain management in referral hospitals found in the Amhara region and to identify associated factors for nurse's knowledge and attitudes toward postoperative pain management.

\section{Methods \\ Study Design and Period}

A multicenter cross-sectional study was conducted to determine Nurses' knowledge and attitude towards postoperative pain management and to identify associated factors. Following ethical approval by the institutional ethical approval committee, the study was done from March 16 April 16/2019.

\section{Study Participants}

The study was done on nurses who were working in DebreBerhan, Debre-Markos, Felege-Hiwot, University of Gondar, Tibebe-Gion, and Dessie referral hospitals. Those all nurses $(n=433)$ working in the surgical (i.e. recovery room, surgical, orthopedic and trauma ward), gynecology and obstetrics and ophthalmology department were included.

The outcome variables included in this study were knowledge and attitude of postoperative pain management. Age, sex, religion, highest level of education attained, training participated on postoperative pain management, availability of pain management course in curriculum of their level of education, work experience in total services and in the surgical area, number and habit of reading updated journals or articles on POP management and place of work (wards/units where nurses are currently working) were considered as independent variables.

In this study, adequate knowledge of postoperative pain management was defined when participants scored $\geq 8$ out of 13 total items of the knowledge scale. ${ }^{24}$ Furthermore, positive attitude towards postoperative pain management was defined as they scored $\geq 56$ out of 70 total scores of the attitude scale. $^{14}$

\section{Data Collection Instrument and Procedure}

Nurses' knowledge and attitudes were measured using the Nurses Knowledge and Attitudes Survey Regarding Pain (NKASRP) scale. This instrument has 39 questions; 22 true/false, 15 multiple choice and 2 case studies. ${ }^{25}$ The tool has been validated elsewhere and reliability was found $0.86 .^{26}$ Before utilizing the tool in our study, the English version was first translated into Amharic (local language) by two translators and again back to English to confirm the correctness of the translation by another two translators. 
Then, expert committee discussed and finalizes the questionnaire with minor modification. The expert committee made modification on some questions for reason not applicable in our set-up. Overall, our final questionnaire contained 27 items. The final questionnaire used is available on request on authors. The internal consistency of the Amharic NKAPH was high (Cronbach's alpha $=0.88$ ).

\section{Analyses}

Each completed questionnaire was checked visually for completeness before fed to computer. The data were entered into Epi-info version 7.0, data clean up and cross-checking was done and it was analyzed by using SPSS version 22.0 software. Descriptive statistics were performed to describe socio-demographic characteristics; knowledge and attitude scales of postoperative pain management.

We investigated the associations between outcome variables and potential associated factors using multivariable binary logistic regression. All factors with p-value $<0.2$ in the bivariable logistic regression were entered into the multivariable logistic regression model. Model fitness was checked using Hosmer-Lemeshow test. Crude and adjusted Odds ratios (ORs) with 95\% confidence intervals (CIs) were reported to measure the strength of association. All statistical tests were two-sided, and a $P$-value $<0.05$ was considered statistically significant.

\section{Results}

\section{Socio-Demographic Characteristics}

A total of 433 questionnaires were distributed over a two months period, of which 395 were completed and returned making a response rate of $91.2 \%$. The majority of participants $(64.1 \%)$ were women. The median age of participants was 28.0 years (Interquartile range of (IQR $=26.0-32.0$, range 22-51 years)). The majority, $249(63.0 \%)$ were in the age between 22 to 29 years. Of the total respondents, $90.6 \%$ of them had a bachelor's degree with work experience of between 1 to 5 years $(58.5 \%)$. Only few 76 (19.2\%) participants got access to read journals or articles regarding postoperative pain management. Furthermore, a few study participants, 66 (16.7\%) had taken postoperative management training (Table 1).

\section{Nurses Postoperative Pain Management Knowledge}

The mean participants' knowledge score was 7.74 with the standard deviation of $(\mathrm{SD}=2.16)$. The majority of participants, $368(93.16 \%)$ scored a mean of 5 and 12, whereas
Table I Socio-Demographic Data of Participants $(n=395)$

\begin{tabular}{|c|c|c|c|}
\hline \multicolumn{2}{|l|}{ Variables } & \multirow{2}{*}{$\begin{array}{l}\text { Frequency } \\
142 \\
253\end{array}$} & \multirow{2}{*}{$\begin{array}{l}\text { Percent } \\
35.9 \\
64.1\end{array}$} \\
\hline Sex & $\begin{array}{l}\text { Male } \\
\text { Female }\end{array}$ & & \\
\hline Age (in years) & $\begin{array}{l}21-29 \\
30-40 \\
>40\end{array}$ & $\begin{array}{l}249 \\
135 \\
11\end{array}$ & $\begin{array}{l}63.0 \\
34.2 \\
2.8\end{array}$ \\
\hline Level of education & $\begin{array}{l}\text { Diploma } \\
\text { Bachelor } \\
\text { Postgraduate }\end{array}$ & $\begin{array}{l}23 \\
358 \\
14\end{array}$ & $\begin{array}{l}5.8 \\
90.6 \\
3.5\end{array}$ \\
\hline Nursing grade & $\begin{array}{l}\text { Staff nurse } \\
\text { Staff midwife }\end{array}$ & $\begin{array}{l}245 \\
150\end{array}$ & $\begin{array}{l}62.0 \\
38.0\end{array}$ \\
\hline $\begin{array}{l}\text { Work experience } \\
\text { (in years) }\end{array}$ & $\begin{array}{l}<1 \\
1-5 \\
6-10 \\
11-15 \\
16-20 \\
>20\end{array}$ & $\begin{array}{l}77 \\
231 \\
70 \\
11 \\
3 \\
3\end{array}$ & $\begin{array}{l}19.5 \\
58.5 \\
17.7 \\
2.8 \\
0.8 \\
0.8\end{array}$ \\
\hline $\begin{array}{l}\text { Work experience in } \\
\text { surgical unit (in } \\
\text { years) }\end{array}$ & $\begin{array}{l}<1 \\
1-5 \\
\geq 6\end{array}$ & $\begin{array}{l}208 \\
184 \\
3\end{array}$ & $\begin{array}{l}52.7 \\
46.6 \\
0.8\end{array}$ \\
\hline Working unit & $\begin{array}{l}\text { Recovery } \\
\text { General surgery } \\
\text { Orthopedic and } \\
\text { trauma } \\
\text { Obstetrics } \\
\text { Fistula \& } \\
\text { gynecology } \\
\text { Ophthalmology }\end{array}$ & $\begin{array}{l}46 \\
77 \\
57 \\
154 \\
46 \\
15\end{array}$ & $\begin{array}{l}11.6 \\
19.5 \\
14.4 \\
39.0 \\
11.6 \\
\\
3.8\end{array}$ \\
\hline $\begin{array}{l}\text { Access to read } \\
\text { journals or articles } \\
\text { in the last year/ } \\
\text { month/week }\end{array}$ & $\begin{array}{l}\text { Yes } \\
\text { No }\end{array}$ & $\begin{array}{l}76 \\
319\end{array}$ & $\begin{array}{l}19.2 \\
80.8\end{array}$ \\
\hline $\begin{array}{l}\text { Previous training on } \\
\text { POP }\end{array}$ & $\begin{array}{l}\text { Yes } \\
\text { No }\end{array}$ & $\begin{array}{l}66 \\
329\end{array}$ & $\begin{array}{l}16.7 \\
83.3\end{array}$ \\
\hline
\end{tabular}

only $8(2.03 \%)$ respondents correctly answered all questions. More than a half, $56.5 \%$ [95\% CI $=(51.6-61.3)]$ had adequate knowledge regarding postoperative pain management. The most correctly answered questions were (questions $1,5,7,8,9,10$, and 12) whereas (questions 2, 3, 4, 11 , and 13) were the most incorrectly answered (Table 2).

Factors Associated with Nurses Postoperative Pain Management Knowledge In the bivariable analyses sex, level of education, getting access to read journals or articles, taking POP management 
Table 2 Nurse's Knowledge on POP Management $(n=395)$

\begin{tabular}{|c|c|c|c|}
\hline Knowledge About POP Management & True (\%) & False (\%) & $\begin{array}{l}\text { Correct } \\
\text { Answer }\end{array}$ \\
\hline I. Pain is what the patient says it is. & $331(83.8)$ & $64(16.2)$ & $\mathrm{T}$ \\
\hline 2. Acute pain lasts for 20 to 30 days. & $143(36.2)$ & $252(63.8)$ & T \\
\hline 3. The most accurate judge of the intensity of the patient's pain is the patient's primary nurse. & $255(64.6)$ & $140(35.4)$ & $\mathrm{F}$ \\
\hline 4. Vital signs are always reliable indicators of the intensity of a patient's pain. & $274(69.4)$ & $|2|(30.6)$ & $\mathrm{F}$ \\
\hline 5. Pain assessment includes onset, duration, variability, location, and intensity of pain. & $346(87.6)$ & $49(12.4)$ & $\mathrm{T}$ \\
\hline 6. Glasgow Coma Scale is a pain assessment tool. & |9| (48.4) & $204(5 I .6)$ & $\mathrm{F}$ \\
\hline 7. When using the WHO pain ladder to treat acute pain, treatment should go from bottom to top. & $258(65.3)$ & $137(34.7)$ & T \\
\hline 8. Using a pain management assessment tool is not integral to POP management. & $144(36.5)$ & $251(63.5)$ & $\mathrm{F}$ \\
\hline 9. Untreated POP delays recovery. & $292(73.9)$ & $103(26.10)$ & $\mathrm{T}$ \\
\hline 10. Effective analgesia is an essential part of POP management. & $342(86.6)$ & $53(13.4)$ & T \\
\hline $\begin{array}{l}\text { II. The recommended route of administration of opioid analgesics with brief, severe pain of sudden } \\
\text { onset such as POP is intramuscular. }\end{array}$ & $234(59.2)$ & $161(40.8)$ & $\mathrm{F}$ \\
\hline 12. Analgesics for POP should initially be given around the clock on a fixed schedule. & $268(67.8)$ & $127(32.2)$ & $\mathrm{T}$ \\
\hline 13. Naloxone antagonizes (reverses) all opiates, but its effect quickly wears off. & $187(47.3)$ & $208(52.7)$ & $\mathrm{F}$ \\
\hline
\end{tabular}

training, and inclusion of pain management course in the curriculum were significantly associated with adequate knowledge. After adjustment, level of education $[\mathrm{AOR}=8.2 ; 95 \%$ $\mathrm{CI}=(2.51-26.83)]$, getting access to read journals or articles $[\mathrm{AOR}=1.83 ; 95 \% \mathrm{CI}=(1.01-3.30)]$, and taking POP management training $[\mathrm{AOR}=8.63 ; 95 \% \mathrm{CI}=(3.67-20.28)]$ were significantly associated with adequate knowledge (Table 3 ).

Accordingly, respondents who have taken POP management training were almost 9 times more likely to have adequate knowledge than those who did not take such training. Similarly, the odds of having adequate knowledge towards POP management was 8 times higher in those respondents who have bachelors' degree and above as compared to diploma holders. The study also revealed that the likelihood of having adequate knowledge was $83 \%$ higher in those study participants who get access to read journals or articles compared to their counterparts (Table 3).

\section{Nurses' Attitude Regarding Postoperative Pain Management}

The median attitude score was 44.0 ( $\mathrm{IQR}=7.0,41-48$, range 22-62). The majority of participants $(\mathrm{n}=338$; $85.57 \%$ ) scored between 37 and 51 whereas 49 (12.4\%) scored higher than 51 points. Only $8.9 \%$ of participants $(95 \% \mathrm{CI}=6.1-11.6)$ had scored $\geq 56$. More than half of the participants strongly agreed that effective analgesia was an

Table 3 Factors Associated with Nurses' POP Management Knowledge $(n=395)$

\begin{tabular}{|c|c|c|c|c|c|}
\hline \multicolumn{2}{|l|}{ Variables } & \multicolumn{2}{|c|}{ Knowledge Status } & \multicolumn{2}{|c|}{ Odds Ratio (95\% Cl) } \\
\hline & & Inadequate & Adequate & COR & AOR \\
\hline Sex & $\begin{array}{l}\text { Male } \\
\text { Female }\end{array}$ & $\begin{array}{l}74 \\
98\end{array}$ & $\begin{array}{l}68 \\
155\end{array}$ & $\begin{array}{l}1.00 \\
1.72(1.136-2.607)^{*}\end{array}$ & $* * *$ \\
\hline Level of education & $\begin{array}{l}\text { Diploma } \\
\text { Bachelor and above }\end{array}$ & $\begin{array}{l}19 \\
153\end{array}$ & $\begin{array}{l}4 \\
219\end{array}$ & $\begin{array}{l}1.00 \\
6.79(2.27-20.38)^{*}\end{array}$ & $\begin{array}{l}1.00 \\
8.20(2.5 I-26.83) * *\end{array}$ \\
\hline Access to journals or articles & $\begin{array}{l}\text { No } \\
\text { Yes }\end{array}$ & $\begin{array}{l}150 \\
22\end{array}$ & $\begin{array}{l}169 \\
54\end{array}$ & $\begin{array}{l}1.00 \\
2.18(1.27-3.75)^{*}\end{array}$ & $\begin{array}{l}1.00 \\
1.83(1.01-3.30)^{* *}\end{array}$ \\
\hline Training & $\begin{array}{l}\text { No } \\
\text { Yes }\end{array}$ & $\begin{array}{l}165 \\
7\end{array}$ & $\begin{array}{l}164 \\
59\end{array}$ & $\begin{array}{l}1.00 \\
8.48(3.76-19.12)^{*}\end{array}$ & $\begin{array}{l}1.00 \\
8.63(3.67-20.28)^{* *}\end{array}$ \\
\hline Curriculum & $\begin{array}{l}\text { No } \\
\text { Yes }\end{array}$ & $\begin{array}{l}170 \\
2\end{array}$ & $\begin{array}{l}212 \\
11\end{array}$ & $\begin{array}{l}1.00 \\
4.41(0.95-19.96)^{*}\end{array}$ & $* * *$ \\
\hline
\end{tabular}

Notes: $1.00=$ Reference, ${ }^{*} \mathrm{p}$-value $<0.2,{ }^{* *} \mathrm{p}$-value $<0.05, * *$ Did not appear. 
essential part of postoperative pain management $(n=210$, $53.2 \%)$. Concerning whether the type of surgery done affects their response to pain management, 155 (39.2\%) agreed while $34(8.6 \%)$ disagreed treatment of POP depending on the type of surgery (Table 4).

\section{Factors Associated with Nurse's}

\section{Postoperative Pain Management Attitude}

In the bivariable analyses, nurses' attitude was significantly associated with sex, level of education, nursing grade, getting access to read journals or articles, taking POP management training, and inclusion of pain management course in the curriculum. In multivariable analyses, level of education $[\mathrm{AOR}=1.65 ; 95 \%$ CI $0.06-0.49$ ], getting access to read journals or articles $[\mathrm{AOR}=2.38$; $95 \% \mathrm{CI}=1.04-5.42]$, taking POP management training [AOR $=50.00 ; 95 \% \mathrm{CI}=2.25-11.10]$, and inclusion of pain management course in the curriculum during preservice training $[\mathrm{AOR}=6.97 ; 95 \% \mathrm{CI}=1.94-25.03$ ] were significantly associated with positive attitude. Those who had a pain management course in the curriculum had almost seven times more likely to have a positive attitude towards POP management compare with their counterparts. Those who had previous POP training had five times in having a positive attitude compared with counterparts (Table 5).

\section{Discussion}

Postoperative pain is a predictable and worrisome, yet a manageable problem. ${ }^{27}$ However, ineffective pain management is a quite common phenomenon across the globe that leads to numerous problems. ${ }^{28}$ This study was aimed to assess nurses' knowledge and attitude towards POP. Our results revealed that more than half had adequate knowledge of postoperative pain management. However, most nurses had poor attitude towards postoperative pain management.

The $56.5 \%$ of adequate knowledge on POP management finding in this study is in line with a study done in the Ashanti region of Ghana in which $52 \%$ had adequate knowledge on postoperative pain management. ${ }^{24}$ However, this finding is higher than the study conducted in Jordan in which only $24.10 \%$ of them had adequate knowledge. ${ }^{21}$ The possible explanation for this variation might be in the current study most of the study participants ( $n=372,94.2 \%)$ are a bachelor and above degree holders which may positively impact their level of knowledge

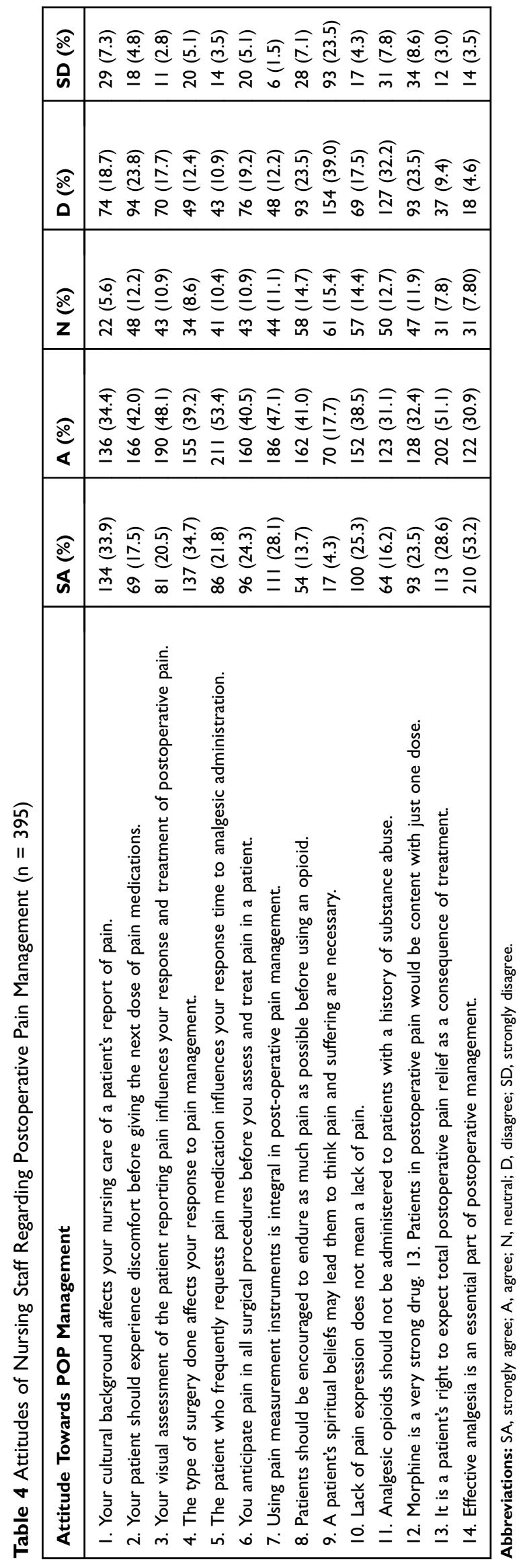


Table 5 Factors Associated Nurse's Attitude Regarding the POP Management $(n=395)$

\begin{tabular}{|c|c|c|c|c|c|}
\hline \multicolumn{2}{|l|}{ Variables } & \multicolumn{2}{|c|}{ Level of Attitude } & \multicolumn{2}{|c|}{ Odds Ratio $(95 \% \mathrm{Cl})$} \\
\hline & & Positive & Negative & COR & AOR \\
\hline Sex & $\begin{array}{l}\text { Male } \\
\text { Female }\end{array}$ & $\begin{array}{l}137 \\
223\end{array}$ & $\begin{array}{l}5 \\
30\end{array}$ & $\begin{array}{l}1.00 \\
3.69(1.40-9.73)^{*}\end{array}$ & $* * *$ \\
\hline Level of education & $\begin{array}{l}\text { Diploma } \\
\text { Bachelor and above }\end{array}$ & $\begin{array}{l}17 \\
343\end{array}$ & $\begin{array}{l}6 \\
29\end{array}$ & $\begin{array}{l}1.00 \\
0.24(0.088-0.65)^{*}\end{array}$ & $\begin{array}{l}1.00 \\
1.65(0.06-0.49)^{* *}\end{array}$ \\
\hline Nursing grade & $\begin{array}{l}\text { Midwifery } \\
\text { Nurses }\end{array}$ & $\begin{array}{l}145 \\
215\end{array}$ & $\begin{array}{l}5 \\
30\end{array}$ & $\begin{array}{l}1.00 \\
4.05(1.53-10.67)^{*}\end{array}$ & \\
\hline Access to journals or articles & $\begin{array}{l}\text { No } \\
\text { Yes }\end{array}$ & $\begin{array}{l}299 \\
61\end{array}$ & $\begin{array}{l}20 \\
15\end{array}$ & $\begin{array}{l}1.00 \\
3.68(1.78-7.58)^{*}\end{array}$ & $\begin{array}{l}* * * \\
2.38(1.04-5.42)^{* *}\end{array}$ \\
\hline Training & $\begin{array}{l}\text { No } \\
\text { Yes }\end{array}$ & $\begin{array}{l}311 \\
49\end{array}$ & $\begin{array}{l}18 \\
17\end{array}$ & $\begin{array}{l}1.00 \\
5.99(2.89-12.42)^{*}\end{array}$ & $\begin{array}{l}1.00 \\
5.00(2.25-11.10)^{* *}\end{array}$ \\
\hline Curriculum & $\begin{array}{l}\text { No } \\
\text { Yes }\end{array}$ & $\begin{array}{l}354 \\
6\end{array}$ & $\begin{array}{l}28 \\
7\end{array}$ & $\begin{array}{l}\text { I.00 } \\
14.75(4.64-46.88)^{*}\end{array}$ & $\begin{array}{l}1.00 \\
6.97(1.94-25.03)^{* *}\end{array}$ \\
\hline
\end{tabular}

Notes: $1.00=$ Reference, ${ }^{*} \mathrm{p}$-value $<0.2,{ }^{* *} \mathrm{p}$-value $<0.05, * * *$ Did not appear.

towards postoperative pain management whereas most of the counterparts were diplomas.

In the current study, one of the most incorrectly answered question by most respondents 255 (64.6\%) was the item which states "most accurate judge of the intensity of the patient's pain". This is in contrast to a study conducted in Pakistan ${ }^{29}$ in which most of the respondents (78.3\%) correctly respond patents' own statements should be accepted as the single most reliable indicator of the presence and intensity of pain. This might be due to in their study, respondents involved in workshops related to postoperative pain management which has a positive impact on their knowledge of how to judge patients' pain.

Our study also revealed that only 161 (40.8\%) respondents correctly answered the item which states

"the recommended route of administration of opioid analgesics with brief, severe pain of sudden onset such as POP is intramuscular".

This finding is lower than a study done in India in which all of the nurses correctly indicated that the intravenous route is the recommended route for the administration of opioid analgesics in those patients. ${ }^{30}$ The possible explanation for this discrepancy may be, in the current study most of the respondents 319 (80.8\%) did not read journals or articles about POP management, but the nursing staff in their study need to stay updated and thereby made efforts to improve their knowledge in their daily practice through different sources.
The current study showed that the level of education has a strong association with respondents' knowledge towards POP management in which those who have bachelor and above are more likely to have adequate knowledge than diploma holders. This finding is consistent with studies conducted in Ghana, Jordan, Greece, and Norway. ${ }^{14,21,22,24,31}$ It is known that knowledge can mainly be acquired through continuing education formally way and these findings indicate that further advanced education positively changes or reshapes nurses' knowledge toward postoperative pain management.

This study revealed that training was significantly associated with study participants' knowledge of POP management. This finding is in line with studies conducted in Pakistan, Brazil, and Jordan. ${ }^{14,27,32}$ This is because those individuals who had taken POP management training could have current information on pain management which can promote knowledge.

The other factor found as significant was reading journals or articles about POP management. The result showed that those who got access to read journals or articles were more knowledgeable than their counterparts. This finding is supported by studies conducted in Poland and Greece. ${ }^{22,33}$ This is because self-education from medical journals can give better knowledge about postoperative pain which is currently the most advisable source of information for clinicians in keeping up to date with evidence-based knowledge.

Our study indicated that nurses had poor attitudes regarding postoperative pain management. Almost 1 in 
10 of participants have, $8.9 \%$ [95\% CI= (6.1-11.6) ] a positive attitude towards POP management. This indicates that most of them have negative attitudes toward POP management which may affect their POP management practice which can contribute for unpleasant or negative patient experiences of pain after surgery. However, this result is higher than the study in Jordan and Bangladesh, in which all of the respondents scored below the passing scale. ${ }^{14,34}$ This difference might be probably due to an educational background in which most of our respondents are a bachelor and above degree holders.

In this study most of the respondents showed good attitudes to some items as they indicate that lack of pain expression does not mean lack of pain; this is because patients may not express their pain due to different reasons such as physical, physiological, etc. These findings are in line with a study done in India. ${ }^{30}$ Study participants in our study agreed that they must anticipate pain before evaluation and management. This is because if they do not expect pain there is no relevance to assessing patients' pain. In addition, most of them agreed that postoperative pain management is part of the management in postoperative care to avoid complications related to pain and to fasten patients' convalescence and part of the patient's rights. This finding is consistent with a study done in Ghana. ${ }^{24}$

In this study, attitude showed significant association with the inclusion of pain management courses in the curriculum in which those who take pain management in postgraduate were more likely to have a positive attitude towards POP management than the counter respondents This finding is in line with a study done in Jordan. ${ }^{35}$ This is because when an education course on pain management is integrated into the curricula, it increases the number of contact teaching hours on pain management providing professionals to cover pain pathophysiology, assessment approaches, management, and barriers to optimal pain management. ${ }^{14,36}$ This may probably impact positively their feeling towards POP management. This would also allow improving knowledge and practice on pain management.

Similarly, those who had taken training on POP management are five times more likely to have a positive attitude towards POP management than those who did not attend the program. This is supported by studies done in different countries across the world. ${ }^{14,22,37-39}$ This is because training may give update information about POP complication and its management currently in the globe that can reshape their attitude positively towards POP management.

This study revealed that there is a significant association between reading journals or articles and study participants' attitude towards POP management. This finding is supported by a study conducted in Greece. ${ }^{22}$ This may be due to reading medical journals or articles that may give them current information about pain and its management which is nowadays the recommended source of medical information for clinicians. Besides, the level of education has a significant association with the respondents' attitude towards POP management which is supported by different research findings done in different countries across the globe. ${ }^{14,21,31,35,36,40}$ This is because education is an indispensable aspect of improving pain knowledge and attitudes towards pain management, ${ }^{14,41,42}$ but this alone is not enough to achieve the goal of adequate pain management.

This study has its own strengths. First, it was multicenter study. Second, it was conducted on referral hospitals where a larger number of nurses were working (includes large sample size). Third, it identified factors associated with adequate knowledge and positive attitude. Fourth, the results were accurate information since it was done in all nurses working in surgical patients. However, our study had some limitations. First, the study tries to assess the postoperative pain management knowledge and attitude of nurses and associated factors, but it does not include their practices. This is because the practice should be assessed by direct observation. Second, although pain management is multidisciplinary, this study focused on the nurses only. Third, since this study was done in different institutions there may be a different clinical experience that may contribute to their knowledge and attitude different which may need multilevel analysis. Fourth, there may be recalling bias in those who did not get the chance to update themselves through different sources. Fifth, informing nurses about the study aims were considered necessary for meeting ethical considerations; however, social desirability bias could have occurred because participants might try to respond in a favorably viewed manner about their knowledge and attitudes towards postoperative pain management. Sixth, the study was conducted in a small number of hospitals which may limit the generalizability of the findings to all nurses working in the country.

\section{Conclusion}

In conclusion, the findings of this study showed that more than half of nurses had adequate knowledge; however, most of them had poor attitudes towards postoperative pain management. Reading journals or articles, taking postoperative pain 
management training, and level of education were significantly associated with good knowledge and a positive attitude towards postoperative pain management. In addition, the inclusion of a pain management course in the curriculum was significantly associated with a positive attitude. We recommend self-learning strategies; nurses should update their knowledge regarding postoperative pain management through continuous professional development, regular in-service shortterm training, and on-line reading. Hospital administration should also organize short-term training, and avail recent articles in the ward in which nurses are working. Moreover, inclusion of POP course in the curriculum is also recommended.

\section{Abbreviations}

AOR, adjusted odds ratio; COR, crude odds ratio; HCP, healthcare professionals; ICU, intensive care unit; IQR, interquartile range; KASRP, knowledge attitude survey regarding pain; POP, postoperative pain; UOG, University of Gondar; WHO, World Health Organization.

\section{Acknowledgments}

The authors would like to thank University of Gondar (financial support), data collectors, and study participants.

\section{Author Contributions}

All authors contributed to data analysis, drafting or revising the article, gave final approval of the version to be published, and agree to be accountable for all aspects of the work. All authors read and approved the final manuscript.

\section{Disclosure}

The authors report no conflicts of interest in this work.

\section{References}

1. American Society of Anesthesiologists Task Force on Acute Pain Management. Practice guidelines for acute pain management in the perioperative setting an updated report by the American Society of Anesthesiologists Task Force on Acute Pain Management. Anesthes. 2012;116(2):248-273. doi:10.1097/ALN.0b013e31823c1030

2. WHO. Size and distribution of the global volume of surgery in 2012 [Internet]. WHO. [cited November 8, 2019]. Available from: http:// www.who.int/bulletin/volumes/94/3/15-159293/en/.

3. Apfelbaum JL, Chen C, Mehta SS, Gan TJ. Postoperative pain experience: results from a national survey suggest postoperative pain continues to be undermanaged. Anesth Analg. 2003;97(2):534-540. doi:10.1213/01.ANE.0000068822.10113.9E

4. Gan TJ, Habib AS, Miller TE, White W, Apfelbaum JL. Incidence, patient satisfaction, and perceptions of post-surgical pain: results from a US national survey. Curr Med Res Opin. 2014;30(1):149-160. doi:10.1185/03007995.2013.860019
5. Gan TJ. Poorly controlled postoperative pain: prevalence, consequences, and prevention. J Pain Res. 2017;10:2287-2298. doi: $10.2147 / \mathrm{JPR}$

6. Admassu WS, Hailekiros AG, Abdissa ZD. Severity and risk factors of post-operative pain in University of Gondar Hospital, Northeast Ethiopa. J Anesth Clin Res. 2016;7(10). doi:10.4172/2155-6148

7. Woldehaimanot TE, Eshetie TC, Kerie MW. Postoperative pain management among surgically treated patients in an Ethiopian hospital. PLoS One. 2014;9(7):e102835. doi:10.1371/journal.pone.0102835

8. Eshete MT, Baeumler PI, Siebeck M, et al. Quality of postoperative pain management in Ethiopia: a prospective longitudinal study. Li Y, editor. PLoS One. 2019;14(5):e0215563. doi:10.1371/journal.pone.0215563

9. Fallatah SMA. Pain knowledge and attitude survey among healthcare professionals at a University Hospital in Saudi Arabia. Med Sci. 2017;5(2):5.

10. Bonkowski SL, Gagne JCD, Cade MB, Bulla SA. Evaluation of a pain management education program and operational guideline on nursing practice, attitudes, and pain management. J Contin Educ Nurs. 2018;49(4):178-185. doi:10.3928/00220124-20180320-08

11. Suwanraj M. Current Practice, Perceived Barriers, and perceived Facilitators of Thai Nurses on Using the Evidence-Based practice on Pain Assessment and Pain Management in Older Adults; Theses Diss;2010.

12. Boric K, Boric M, Boric T, Puljak L. Analysis of perioperative pain management in vascular surgery indicates that practice does not adhere with guidelines: a retrospective cross-sectional study. J Pain Res. 2017;10:203-209. doi:10.2147/JPR.S123894

13. Tomaszek L, Fenikowski D, Gawron D, Komotajtys H. Comparative efficacy of continuous infusion of bupivacaine/fentanyl and ropivacaine/fentanyl for paediatric pain control after the Ravitch procedure and thoracotomy. A prospective randomized study. Biomed Pap Med Fac Univ Palacky Olomouc Czech Repub. 2018. doi:10.5507/ bp.2018.072

14. Shoqirat N, Mahasneh D, Al-Khawaldeh O, Al Hadid L. Nurses' knowledge, attitudes, and barriers toward pain management among postoperative patients in Jordan. J Perianesth Nurs. 2019;34(2):359367. doi:10.1016/j.jopan.2018.05.012

15. Nickitas DM. A Global Health Agenda: It Is Who We Are. Available from: https://www.nursingeconomics.net/necfiles/2016/JA16/158.pd. Accessed December 10, 2019.

16. Van Niekerk LM, Martin F. Tasmanian nurses' knowledge of pain management. Int J Nurs Stud. 2001;38(2):141-152. doi:10.1016/ S0020-7489(00)00053-5

17. Brennan FP, Carr DB, Cousins MJ. Pain management: a fundamental human right. Anesth Analg. 2007;105(1):205-221. doi:10.1213/01. ane.0000268145.52345.55

18. Chatchumni M, Namvongprom A, Eriksson H, Mazaheri M. Thai nurses' experiences of post-operative pain assessment and its' influence on pain management decisions. BMC Nurs. 2016;15:12. doi:10.1186/s12912-016-0136-8

19. Tomaszek L, Tomalak W, Gajdosz R, Buchwald J. Intermittent thoracic epidural administration of bupivacaine-morphine versus intravenous infusion of morphine after thoracic surgery in children and adolescents. Anest Ratow. 2015;9:260-268. doi: 10.3389/fnbeh.2015.00215

20. Tomaszek L, Fenikowski D, Komotajtys H, Gawron D. Ropivacaine/ Fentanyl vs. Bupivacaine/Fentanyl for pain control in children after thoracic surgery: a randomized study. Pain Manag Nurs. 2019; 20 (4):390-397.

21. Nuseir K, Kassab M, Almomani B. Healthcare providers' knowledge and current practice of pain assessment and management: how much progress have we made? Pain Res Manage. 2016;2016:1-7. doi: $10.1155 / 2016 / 8432973$

22. Kiekkas P, Gardeli P, Bakalis N, et al. Predictors of nurses' knowledge and attitudes toward postoperative pain in Greece. Pain Manage Nurs. 2015;16(1):2-10. doi:10.1016/j.pmn.2014.02.002 
23. Zeb A, Riaz M, Emmanual S, Rehman N, Qudrat S. Barriers to evidence based nursing practice in tertiary care hospitals of Peshawar, Pakistan. Biomed J Sci Tech Res. 2018;8(1):5.

24. Menlah A, Garti I, Amoo SA, Atakro CA, Amponsah C, Agyare DF. Knowledge, attitudes, and practices of postoperative pain management by nurses in selected district hospitals in Ghana. SAGE Open Nurs. 2018;4:237796081879038. doi:10.1177/2377960818790383

25. Knowledge and Attitudes Survey Regarding Pain developed by Betty Ferrell, RN, PhD, FAAN and Margo McCaffery, RN, MS, FAAN, (http://prc.coh.org), revised 2014.

26. Zanolin ME, Visentin M, Trentin L, Saiani L, Brugnolli A, Grassi M. A questionnaire to evaluate the knowledge and attitudes of health care providers on pain. J Pain Symptom Manage. 2007;33(6):727736. doi:10.1016/j.jpainsymman.2006.09.032

27. Bodian CA, Freedman G, Hossain S, Eisenkraft JB, Beilin Y. The visual analog scale for pain: clinical significance in postoperative patients. Anesthesiology. 2001;95(6):1356-1361.

28. Dunwoody CJ, Krenzischek DA, Pasero C, Rathmell JP, Polomano RC. Assessment, physiological monitoring, and consequences of inadequately treated acute pain. $J$ Perianesthesia Nurs Off J Am Soc PeriAnesthesia Nurses. 2008;23(1 Suppl):15-27.

29. Zeb A, Farhana J, Marym U, Bi NB. Nurses knowledge regarding post-operative pain management. $J$ Healthcare Commun. 2019;4(1) doi:10.4172/2472-1654.100151

30. Dongara AR, Shah SN, Nimbalkar SM, Phatak AG, Nimbalkar AS. Knowledge of and attitudes regarding postoperative pain among the pediatric cardiac nursing staff: an Indian experience. Pain Manage Nurs. 2015;16(3):314-320. doi:10.1016/j.pmn.2014.08.009

31. Smeland AH, Twycross A, Lundeberg S, Rustøen T. Nurses' knowledge, attitudes and clinical practice in pediatric postoperative pain management. Pain Manage Nurs. 2018;19(6):585-598. doi:10.1016/ j.pmn.2018.04.006

32. Dos Santos Silva MA, de Mattos Pimenta CA, de Cruz DALMD. Treinamento e avaliação sistematizada da dor: impacto no controle da dor do pós-operatório de cirurgia cardíaca. Revista Da Escola De Enfermagem da USP. 2013;47(1):84-92. doi:10.1590/S0080-623420 13000100011
33. Tomaszek L, Dębska G. Knowledge, compliance with good clinical practices and barriers to effective control of postoperative pain among nurses from hospitals with and without a "Hospital without pain” certificate. J Clin Nurs. 2018;27(7-8):1641-1652. doi:10.1111/ jocn.2018.27.issue-7pt8

34. Basak S. Knowledge and attitudes of nurses and their practices regarding post-operative pain management in Bangladesh. Palliative Care. 2010;12.

35. Al Qadire M, Al Khalaileh M. Effectiveness of educational intervention on Jordanian nurses' knowledge and attitude regarding pain management. Br J Med Med Res. 2014;13:1460.

36. Ho SE, Choy YC, Rozainiee A. Survey of nurses' knowledge and attitude regarding post operative pain management at a teaching hospital in Malaysia. Med Health. 2009;4:47-52.

37. Abdalrahim MS, Majali SA, Stomberg MW, Bergbom I. The effect of postoperative pain management program on improving nurses' knowledge and attitudes toward pain. Nurse Educ Pract. 2011;11 (4):250-255. doi:10.1016/j.nepr.2010.11.016

38. Aziato L, Adejumo O. Determinants of nurses' knowledge gap on pain management in Ghana. Nurse Educ Pract. 2014;14(2):195-199. doi:10.1016/j.nepr.2013.08.004

39. Mashayekhi F, Kamali A. Effect of training on knowledge and attitude of nurses toward pain management: a quasi-experimental study. Crit Care Nurs. 2019; In Press. doi:10.5812/ccn

40. Rognstad M-K, Fredheim OMS, Johannessen TEB, et al. Attitudes, beliefs and self-reported competence about postoperative pain among physicians and nurses working on surgical wards: attitudes, beliefs and self-reported competence. Scand J Caring Sci. 2012;26(3):545552. doi:10.1111/j.1471-6712.2011.00964.x

41. Vickers N, Wright S, Staines A. Surgical nurses in teaching hospitals in Ireland: understanding pain. Br J Nurs. 2014;23(17):924-929. doi:10.12968/bjon.2014.23.17.924

42. Shoqirat N. 'We are nurses, they are doctors': barriers to nurses' roles in pain management following surgery in Jordan. Int J Nurs Pract. 2015;21(2):200-206. doi:10.1111/ijn.2015.21.issue-2

\section{Publish your work in this journal}

Patient Related Outcome Measures is an international, peer-reviewed, open access journal focusing on treatment outcomes specifically relevant to patients. All aspects of patient care are addressed within the journal and practitioners from all disciplines are invited to submit their work as well as healthcare researchers and patient support groups.
The manuscript management system is completely online and includes a very quick and fair peer-review system. Visit http://www. dovepress.com/testimonials.php to read real quotes from published authors. 